\title{
Effects of an emotional regulation program on maladaptive cognitive emotion regulation, stress, anxiety, and postpartum depression among South Korean mothers of premature infants in the neonatal intensive care unit
}

\author{
Hyo Sin Choi ${ }^{1}$, Kyung Eun Lee ${ }^{2}$, Yeonghee Shin ${ }^{3}$ \\ ${ }^{1}$ Assistant Professor, Department of Nursing, Daegu Health College, Daegu; ${ }^{2}$ Assistant Professor, Department of Nursing, Keimyung College University, Daegu; \\ ${ }^{3}$ Professor, College of Nursing, Keimyung University, Daegu, Korea
}

\begin{abstract}
Purpose: This study aimed to evaluate the effects of a rational emotive behavior therapy (REBT)-based emotional regulation program for mothers of premature infants in the neonatal intensive care unit (NICU). Methods: The study utilized a nonequivalent control group pretest-posttest design. Seventeen mothers were recruited for the experimental group and 21 mothers for the control group. Data were collected from July 9, 2018, to Oct 12, 2018 from mothers of premature infants in the NICU regarding parental stress, state anxiety, depression, and maladaptive cognitive emotion regulation. The experimental group received eight sessions of the REBT-based emotional regulation program for 3-4 weeks, and the control group only received standard nursing care. Results: Significant differences were found between the two groups in maladaptive cognitive emotion regulation $(Z=-3.88$, $p<.001)$, stress $(Z=-2.76, p=.006)$, state anxiety $(Z=-3.72, p<.001)$, and postpartum depression $(Z=-2.62, p=.009)$ after the intervention in the experimental group. Conclusion: The REBT-based emotional regulation program for mothers of premature infants was effective for reducing maladaptive cognitive emotion regulation, stress, anxiety, and postpartum depression. Therefore, it may be necessary to provide an REBT-based emotional regulation program for mothers of premature infants in the NICU in clinical practice.
\end{abstract}

Key words: Premature infants; Mother; Neonatal intensive care units; Anxiety; Depression

\section{Corresponding author Yeonghee Shin \\ https://orcid.org/0000-0003-4735-6904}

College of Nursing, Keimyung University,

1095 Dalgubeol-daero, Dalseo-gu, Daegu 42601, Korea

TEL +82-53-320-4596 FAX +82-53-580-3916

E-MAIL yeonghees27@gmail.com

*This article was adapted from a thesis by Hyo Sin Choi in partial fulfillment of the requirements for the dissertation at Keimyung University of Korea.

Received Oct 14, 2020 Revised Nov 16, 2020 Accepted Nov 17, 2020

\section{INTRODUCTION}

Although the birth rate in South Korea continues to decrease, the percentage of premature infants rose to $6.6 \%$ in 2019 [1]. Premature infants are admitted to the neonatal intensive care unit (NICU), where they may stay for months to receive medical treatment and close monitoring due to being born with weak immunity and underdeveloped organs [2]. The unexpected birth of a premature infant and subsequent admission to the NICU can be a traumatic event for mothers of premature infants [3].

Mothers of premature infants may believe that giving birth to an unhealthy child is their own fault, causing them to experience psychological stress [4]. Mothers of premature infants experience a deep sense of loss and tend to view childbirth in a much more negative manner as they repeatedly think back to the circumstances surrounding the childbirth [5]. In the NICU, a mother of a premature infant may experience even greater stress from the unfamiliar environment, the uncertainty or lack of information about the prognosis of her child, limited physical contact with her child, and the thought of her (a) This is an Open Access article distributed under the terms of the Creative Commons Attribution NonCommercial License (http://creativecommons.org/licenses/by-nc/4.0/) which permits unrestricted noncommercial use, distribution, and reproduction in any medium, provided the original work is properly cited. 
child suffering during surgery or examinations [6]. These experiences of emotional distress are related to maladaptive cognitive emotion, which may result in negative emotions such as stress, anxiety, and depression, in mothers of premature infants in the NICU [7]. Approximately $23 \%-44 \%$ of mothers of premature infants in the NICU suffer from acute stress disorder [8]. According to a review study of 26 papers, $44 \%$ of mothers of premature infants experienced postpartum depression [9], and Lee and Ju [10] reported a very high percentage, at $86.1 \%$. During the postpartum period, mothers experience many psychological and emotional challenges from the build-up of physical stress due to postpartum pain, lactation, lack of sleep, and overall adjustment to their new role as a mother [11]. This stress and psychological suffering may cause anxiety and depression, which can reduce self-confidence and interfere with the formation of a healthy parent-child relationship, thereby having a high likelihood of negatively affecting the cognitive, social, and emotional development of the child [12].

Rational emotive behavior therapy (REBT), which emphasizes the fact that human beliefs have emotional and behavioral consequences, has been reported to be useful for dealing with negative emotions, such as stress, anxiety, and depression. People with irrational beliefs exhibit negative emotions, such as excessive anxiety, resentment, blame, and despair. REBT promotes disputing irrational beliefs and cultivating rational, valid, efficient, and self-critical cognition [13]. Applying an REBT-based emotional regulation program to mothers of premature infants in the NICU with negative emotions has the potential not only to reduce mothers' negative feelings, but also to help them form positive parent-child relationships.

Previous studies have tested the effects of REBT on reducing negative emotions such as stress, anxiety, depression, and anger [14]. Studies in South Korea that applied REBT have focused on stress, anxiety, and depression reduction among children, adolescents, and middle-aged women [15], and alleviation of negative emotions, such as job stress, anxiety, depression, and anger among nurses [16]. However, to our knowledge, no REBT-based interventional studies have been conducted among mothers of premature infants in the NICU. Accordingly, the present study applied an REBT-based emotion regulation program and tested its effects on reducing stress, state anxiety, postpartum depression, and maladaptive cognitive emotion regulation (MCER) for mothers of premature infants. The hypotheses of the study were as follows:

- Hypothesis 1: There will be a significant difference between the experimental and control groups in the change of the MCER score after the intervention .
- Hypothesis 2: There will be a significant difference between the experimental and control groups in the change of the stress score after the intervention.

- Hypothesis 3: There will be a significant difference between the experimental and control groups in the change of the state anxiety score after the intervention.

- Hypothesis 4: There will be a significant difference between the experimental and control groups in the postpartum depression score after the intervention.

\section{METHODS}

\section{Study Design}

This study used a pretest-posttest, nonequivalent quasi-experimental design to develop an REBT-based emotion regulation program for mothers of premature infants in the NICU and to test its effects on MCER, stress, state anxiety, and postpartum depression.

\section{Participants}

Participants included mothers who gave birth to a premature infant admitted to the NICU at A university hospital in D city, and mothers who satisfied the following inclusion criteria were selected: gave birth to a premature infant for the first time, with a gestational age of less than 28 weeks and a birth weight of more than 1,000 $\mathrm{g}$ and less than 2,500 g; were over 18 years old; had a spouse; were able to read, write, and communicate in Korean; understood the intent of this study and wished to participate; gave birth to a premature infant with no congenital defects or complications; and gave birth and was discharged from the hospital within 1 week.

The sample size needed for the study was calculated using $\mathrm{G}^{*}$ Power 3.1.9.2. In a meta-analysis of 105 cognitive behavioral consultation studies including REBT, the effect size of the negative aspects of stress, anxiety, and depression was 1.12 , indicating a large effect size [17]. When the parameters were set to the effect size of the negative variables addressed through cognitive behavioral counseling (1.12) [17], a significance level of .05 , and a statistical power of .80 , the sample size needed for testing the mean difference between two groups was 17 per group. The actual power of the study was calculated to be 81 .

Three participants dropped out in the experimental group for personal health reasons $(n=1)$ and failure to attend four or more sessions $(\mathrm{n}=2)$. Consequently, a total of 38 participants (21 in the control group and 17 in the experimental group) were included in the final analysis. 


\section{Composition and Operation of an Rational Emotive Behavior Therapy-based Emotion Regulation Program}

The initial draft of the program was designed by a researcher, the first author of this study, based on an analysis of existing literature and needs surveys on emotion regulation programs. Five South Korean and 10 international studies on emotional regulation programs for mothers of premature infants from January 2001 to November 2017 were analyzed based on prior studies that used Ellis's [13] REBT theory to reduce negative emotions.

The emotion regulation program consisted of cognitive, emotional, and behavioral dissonance. Dissonance is an active technique that helps the client self-evaluate how useful their belief system is [13]. Educational dissonance, questioning techniques, and cognitive tasks were used for cognitive dissonance; creating coping statements and rational emotive imagery were used for emotional dissonance; and rational role reversal and behavior reinforcement were used for behavioral dissonance. The content validity of the initial program was tested by a seven-member expert panel using the content validity index (CVI) with respect to the appropriateness, applicability, and usefulness of the program. The expert panel comprised one psychiatrist, one clinical psychology expert, one counseling and educational psychology expert, two nursing professors, and two nurses with more than 10 years of NICU experience. The CVI was calculated to be more than .80 .

The program's aim was to help mothers who shared the common experience of a NICU admission to identify their own irrational beliefs through the REBT-based emotion regulation program and to assist them in changing their negative emotions to more positive emotions through the process of finding appropriate, rational beliefs. Considering that the participants in the program were postpartum mothers, and the timing of infants' NICU discharge is different, a long-term program is not appropriate and the effectiveness of the counseling program is seen in a total of eight to 10 sessions [16]; this study conducted of a total of eight sessions. The study was designed to be conducted two to three times a week, for 3-4 weeks, based on prior studies of intervention programs for NICU inpatient mothers [8]. Each session was 70 minutes, with 15 minutes of introduction, 40 minutes of activities, and 15 minutes of closing [16]. The program was conducted during the NICU hospitalization of the baby, and the small group was run by the researcher.

The researcher has more than 10 years of work experience in the NICU of the university hospital, and has experience in teaching child nursing. Prior to conducting this study, the researcher completed the cognitive behavioral therapy special- ist course at the Korea Institute for Counseling and Development's Lifelong Education Center in July 2017 and obtained a second-degree certificate of cognitive behavioral psychotherapy. In addition, the researcher participated in the group counseling program of the Korea REBT Cognitive Behavioral Treatment Institute and completed the 30-hour course.

After the program was fully completed, each participant was given a certificate of program completion and a gift voucher. In this study, groups were composed of 3-5 people based on the timing of the births and the needs surveys. A small group size can foster positive support and modeling among mothers, and it can be an opportunity for in-depth empathy and mutual assistance [18]. The specific composition and operating methods of the program are shown in Table 1.

\section{Study Tools}

\section{1) Maladaptive cognitive emotion regulation (MCER)}

To measure MCER, we used the MCER subdomains of the Cognitive Emotion Regulation Questionnaire (CERQ), which was originally developed by Garnefski et al. [7] and subsequently translated into Korean by Kim [19]. The original CERQ was designed to measure the cognitive dimensions of emotional regulation after experiencing a negative event. This study used 16 items in four categories: 1) self-blame; 2) other-blame; 3) rumination (thinking about the feelings and thoughts related to the negative event), and 4) catastrophizing (assuming that they are in the worst situation). Each item was graded on a 5-point scale with 1 point for "almost never" and 5 points for "always". The total score ranged between 16 and 80 points, with higher total scores indicating a higher level of MCER. The reliability of the tool was assessed using Cronbach's $\alpha$, which was .83 in the study by Kim [19] and .94 in the present study.

\section{2) Stress}

To measure stress, we used the original Parental Stressor Scale for NICU, which was translated, modified, and supplemented by Jeon [6]. This tool was originally designed to measure parental stress caused by the physical, psychological, and social environment of the pediatric intensive care unit, and was modified by Miles et al. [20] for the NICU. This study used 20 items in 4 categories: 1) NICU environment; 2) appearance and treatment of the infant; 3) relationship with the infant and change in the parental role; and 4) communication with medical staff. Each item was graded on a 5-point scale with 1 point for "never worry" and 5 points for "worry a lot". The total score ranged between 20 and 100 points, with higher total scores indicating a higher level of stress. The reliability of the tool was shown by a Cronbach's $\alpha$ of .91 in the study by 
Table 1. Composition and Operation of the Rational Emotive Behavior Therapy-based Emotion Regulation Program for Mothers of Premature Infants in the Neonatal Intensive Care Unit

\begin{tabular}{|c|c|c|c|c|c|}
\hline Session & Topic & Goals & $\begin{array}{l}\text { Dissonance } \\
\text { technique }\end{array}$ & Program details & Media \\
\hline 1 & $\begin{array}{l}\text { Building } \\
\text { intimacy }\end{array}$ & $\begin{array}{l}\text { Understanding the } \\
\text { program goals }\end{array}$ & Cognitive dispute & $\begin{array}{l}\text {-Intro: Introduction of presider and participants } \\
\text { - Activities } \\
\text { - Sharing feelings after seeing child in the NICU and emotions after } \\
\text { giving birth (situational, cognitive, and emotional expressions) } \\
\text { - Explanation of program goals and introduction of REBT } \\
\text { - Closing: Writing of pledge and pretest survey }\end{array}$ & $\begin{array}{l}\text { - Pretest questionnaire } \\
\text { - Pledge } \\
\text { - Workbook }\end{array}$ \\
\hline 2 & $\begin{array}{l}\text { Exploring } \\
\text { negative } \\
\text { emotions }\end{array}$ & $\begin{array}{l}\text { Identifying } \\
\text { negative emotions } \\
\text { and } \\
\text { understanding } \\
\text { cognitive } \\
\text { processes }\end{array}$ & Cognitive dispute & $\begin{array}{l}\text {-Intro: Presentation of cases involving negative events and } \\
\text { inappropriate negative emotions (stress, anxiety, and depression) } \\
\text { - Activities: } \\
\text { - Write event-emotion record logs } \\
\text { - Use pictures and text to express how strongly inappropriate } \\
\text { negative emotions are felt } \\
\text { - Learn about the importance of cognition } \\
\text { - Differentiation between cognition and emotion } \\
\text { - Closing: Task after explaining cognition record log (event, emotion, } \\
\text { and automatic thought) }\end{array}$ & $\begin{array}{l}\text { - Workbook } \\
\text { (emotional terms) }\end{array}$ \\
\hline 3 & $\begin{array}{l}\text { Examining the } \\
\text { causes of } \\
\text { negative } \\
\text { emotions (1) }\end{array}$ & $\begin{array}{l}\text { Understanding } \\
\text { cognitive } \\
\text { distortion and } \\
\text { irrational beliefs }\end{array}$ & Cognitive dispute & $\begin{array}{l}\text { - Intro: Detailed explanation about types of cognitive distortion } \\
\text { - Activities: } \\
\text { - Think about cognitive distortions I use } \\
\text { - Practice cognitive reconstruction } \\
\text { - Differentiate between irrational and rational beliefs } \\
\text { - Closing: Read } 11 \text { irrational beliefs, task of finding ones that apply to } \\
\text { oneself }\end{array}$ & - Workbook \\
\hline 4 & $\begin{array}{l}\text { Examining the } \\
\text { causes of } \\
\text { negative } \\
\text { emotions (2) }\end{array}$ & $\begin{array}{l}\text { Identifying one's } \\
\text { own irrational } \\
\text { beliefs }\end{array}$ & Cognitive dispute & $\begin{array}{l}\text {-Intro: Introduction of cases involving irrational beliefs } \\
\text { - Activities: } \\
\text { - Finding one's own irrational beliefs related to giving birth to a } \\
\text { premature infant (self-blame, other-blame, rumination, and } \\
\text { catastrophizing) } \\
\text { - Identifying effects of irrational beliefs on emotions } \\
\text { - Practice re-interpretation of situational, cognitive, and emotional } \\
\text { processes } \\
\text {-Closing: Explanation of how to write emotional diary (1) and task }\end{array}$ & - Workbook \\
\hline 5 & $\begin{array}{l}\text { Correcting the } \\
\text { causes of } \\
\text { negative } \\
\text { emotions (1) }\end{array}$ & $\begin{array}{l}\text { Finding rational } \\
\text { alternative beliefs }\end{array}$ & $\begin{array}{l}\text { Cognitive and } \\
\text { emotional dispute }\end{array}$ & $\begin{array}{l}\text {-Intro: Examples of dissonance for irrational beliefs (dissonance based } \\
\text { on logic, reality, and practicality) } \\
\text {-Activities: } \\
\text { - Re-interpretation of situational, cognitive, and emotional processes } \\
\text { - Practice dissonance for one's own irrational beliefs } \\
\text { - Learn skills to rationally express situational, cognitive, and } \\
\text { emotional processes } \\
\text { - Closing: Read } 11 \text { rational alternative beliefs, task of repeatedly } \\
\text { practicing rational coping statements }\end{array}$ & - Workbook \\
\hline 6 & $\begin{array}{l}\text { Correcting the } \\
\text { causes of } \\
\text { negative } \\
\text { emotions (2) }\end{array}$ & $\begin{array}{l}\text { Identifying the } \\
\text { emotional } \\
\text { consequences of } \\
\text { irrational/rational } \\
\text { beliefs }\end{array}$ & $\begin{array}{l}\text { Cognitive and } \\
\text { emotional } \\
\text { dispute }\end{array}$ & $\begin{array}{l}\text {-Intro: Examples of rational coping statements for beliefs that cause } \\
\text { stress, depression, and anxiety and sharing one's own coping } \\
\text { statements } \\
\text { - Activities: } \\
\text { - Compare one's own emotional consequences as a result of } \\
\text { irrational beliefs to emotional consequences when changed to } \\
\text { rational beliefs } \\
\text { - Understand and apply rational emotive imagery technique for a } \\
\text { recent event that caused negative emotions } \\
\text { - Closing: Explanation of how to write emotional diary (2) and task }\end{array}$ & - Workbook \\
\hline 7 & $\begin{array}{l}\text { Training for } \\
\text { applying to } \\
\text { daily life }\end{array}$ & $\begin{array}{l}\text { Understand the } \\
\text { relationship } \\
\text { between cognition } \\
\text { and emotion and } \\
\text { how to apply it to } \\
\text { daily life }\end{array}$ & $\begin{array}{l}\text { Cognitive, } \\
\text { emotional, and } \\
\text { behavioral } \\
\text { dispute }\end{array}$ & $\begin{array}{l}\text { - Intro: Sharing emotional diary cases about events that caused negative } \\
\text { emotions after giving birth } \\
\text { - Activities: } \\
\text { - Act out situations that could trigger negative emotions related to } \\
\text { giving birth to a premature infant } \\
\text { - Role playing: Practice how to cope with irrational beliefs } \\
\text { - Complement each other for changing to appropriate emotions and } \\
\text { exchange opinions } \\
\text { - Closing: Apply to daily life according to rational beliefs/explanation } \\
\text { of method for behavioral re-enforcement according to rational beliefs } \\
\text { and task }\end{array}$ & - Workbook \\
\hline 8 & Closing & $\begin{array}{l}\text { Positive } \\
\text { self-statements } \\
\text { through } \\
\text { confirmation of } \\
\text { changes }\end{array}$ & $\begin{array}{l}\text { Cognitive and } \\
\text { behavioral } \\
\text { dispute }\end{array}$ & $\begin{array}{l}\text { - Intro: Write a letter complimenting oneself } \\
\text { - Activities: } \\
\text { - Discuss changes that have occurred after participating in the } \\
\text { program and making pledges } \\
\text { - Closing: Presentation of certificate of completion, posttest survey, and } \\
\text { program satisfaction survey consisting of subjective statements }\end{array}$ & $\begin{array}{l}\text { - Workbook } \\
\text { - Certificate of } \\
\text { completion } \\
\text { - Review } \\
\text { - Posttest survey } \\
\text { - Satisfaction survey }\end{array}$ \\
\hline
\end{tabular}

NICU, neonatal intensive care unit; REBT, rational emotive behavior therapy. 
Jeon [6] and .94 in the present study.

\section{3) State anxiety}

To measure state anxiety, we used the State-Trait Anxiety Inventory (STAI) form-Korean YZ (STAI-KYZ), which was translated and standardized by Hahn et al. [21] based on the STAI-Y originally developed by Spielberger et al. [22]. The original tool contains state and trait anxiety scales, which consist of 20 items each. We used the state anxiety scale, which measures the emotions of tension and worry caused by a particular situation, as these emotions can be controlled by situational factors. Each item was graded on a 4-point scale with 1 point for "not at all" and 4 points for "very much so". The total score ranged between 20 and 80 points, with higher total scores indicating a higher level of anxiety. The reliability of the state scale was confirmed by a Cronbach's $\alpha$ of .92 in the study by Hahn et al. [21] and .93 in the present study.

\section{4) Postpartum depression}

To measure postpartum depression, we used the Edinburgh Postnatal Depression Scale-Korean Version (EPDS-K), developed by Cox et al. [23] and translated by Han et al. [24]. This scale consists of 10 items graded on a 4-point scale with 0 points for "always so" and 3 points for "not at all". The items included symptoms such as depression, anxiety, guilt, and suicidal ideation in the past week. The total score ranged between 0 and 30 points, with higher scores indicating a higher level of postpartum depression. Han et al. [24] used 10 points as the cut-off for depression, classifying a score of less than 10 points as indicating non-depression, 10-12 points as corresponding to mild depression, and more than 13 points as indicating severe depression. The reliability of the tool was assessed using Cronbach's $\alpha$, which had a value of .85 in the study by Han et al. [24] and .90 in the present study.

\section{Data Collection}

The recruitment of participants was carried out between July 9 and October 12, 2018, after receiving approval from the Institutional Review Board (IRB) of Keimyung University (IRB No. 40525-201805-HR-35). After explaining the purpose and significance of the research to representatives of several university hospitals, the research was conducted at A university hospital, which allowed the research to proceed. To maintain accuracy and consistency in data collection, one nurse with over 10 years of experience in the neonatal intensive care unit was employed as a research assistant, and trained for 2 hours on the content, compilation method, and caution points of the questionnaire for data collection. The research assistant completed IRB training considering the role played by the re- search assistant in the study.

The procedures for the recruitment of participants were as follows: The researcher attached a poster on the bulletin board in the NICU. When someone expressed interest in the study, the NICU nurse got in touch with the researcher. The researcher directly provided information to mothers of premature infants in the NICU regarding the goals and objectives of the study, the benefits and risks of participating in the study, and confidentiality. Written consent was obtained from mothers who voluntarily agreed to participate in the study. The researcher assigned subject identification codes to protect personal information, and promised to keep the collected survey data for 3 years and then discard it using a document shredder.

To prevent the diffusion of the experimental treatment, mothers of premature infants who gave birth in July 2018 were assigned to the control group and those who gave birth during August or September 2018 were assigned to the experimental group. A pretest survey was conducted on both groups to investigate the general characteristics, characteristics of premature infants, MCER, stress, state anxiety, and postpartum depression. The questionnaire survey was completed by each mother and an explanation was provided for parts that were difficult to understand. The pretest survey was conducted 7-10 days after childbirth. The experimental group started the program after the pretest survey.

Mothers of premature infants in the NICU who were assigned to the control group did not receive any intervention, but took part in the posttest survey, which was conducted 3-4 weeks after the pretest survey for the control group and during session 8 for the experimental group.

\section{Data Analysis}

The data collected in the present study were analyzed using SPSS version 21.0 (IBM Corp., Armonk, NY, USA). The general characteristics of the participants were analyzed in terms of frequency, percentage, mean, and standard deviation (SD). Meanwhile, the $x^{2}$ test, Fisher's exact test, and linear-by linear association method were used to test the homogeneity of the general characteristics in the experimental and control groups. The dependent variables-MCER, stress, state anxiety, and postpartum depression-were analyzed using the MannWhitney U-test, a non-parametric mean comparison method. The pretest-posttest differences in the experimental and control groups were analyzed using the Wilcoxon signed rank test, a non-parametric paired test. The Mann-Whitney U-test was used for group comparison with respect to the amount of pretest-posttest change for hypothesis testing. 


\section{RESULTS}

\section{General Characteristics of Participants and Homo- geneity Testing}

The characteristics of participants and the results of homogeneity testing are shown in Table 2 . Since there were no significant differences in the general characteristics between the experimental and control groups, the two groups were determined to be homogeneous.

\section{Homogeneity Testing of Pretest Dependent Variables}

When the homogeneity of the pretest dependent variables of mothers of premature infants was tested, no significant differences were found in MCER, stress, state anxiety, and postpartum depression between the two groups (Table 3)

\section{Hypothesis Testing}

The experimental group showed a significant decrease in

Table 2. General Characteristics of Participants and Homogeneity Testing $(N=38)$

\begin{tabular}{|c|c|c|c|c|c|c|c|}
\hline \multirow{2}{*}{ Variables } & \multirow{2}{*}{ Characteristics } & \multirow{2}{*}{ Categories } & \multirow{2}{*}{$\frac{\text { Total }(\mathrm{n}=38)}{\mathrm{n}(\%) \text { or } \mathrm{M} \pm \mathrm{SD}}$} & \multirow{2}{*}{$\frac{\text { Exp. }(n=17)}{n(\%) \text { or } M \pm S D}$} & \multirow{2}{*}{$\begin{array}{c}\text { Cont. }(\mathrm{n}=21) \\
\mathrm{n}(\%) \text { or } \mathrm{M} \pm \mathrm{SD}\end{array}$} & \multirow{2}{*}{$\begin{array}{l}x^{2} \text { or } \mathrm{Z} \text { or } \\
p \text { for trend }\end{array}$} & \multirow[b]{2}{*}{$p$} \\
\hline & & & & & & & \\
\hline \multirow[t]{22}{*}{ Maternal } & Age (year) & & $32.5 \pm 3.6$ & $32.9 \pm 3.7$ & $32.1 \pm 3.5$ & 0.78 & .434 \\
\hline & \multirow[t]{2}{*}{ Education level } & High school & $9(23.7)$ & $2(11.8)$ & $7(33.3)$ & 2.42 & .148 \\
\hline & & College or above & $29(76.3)$ & $15(88.2)$ & $14(66.7)$ & & \\
\hline & \multirow{3}{*}{$\begin{array}{l}\text { Employment } \\
\text { status }\end{array}$} & Employed & $3(7.9)$ & $1(5.9)$ & $2(9.5)$ & 1.37 & $.312^{\dagger}$ \\
\hline & & On temporary leave & $9(23.7)$ & $7(41.2)$ & $2(9.5)$ & & \\
\hline & & Unemployed & $26(68.4)$ & $9(52.9)$ & $17(81.0)$ & & \\
\hline & \multirow{3}{*}{$\begin{array}{l}\text { Monthly income } \\
\text { (10,000 won) }\end{array}$} & $\leq 200$ & $3(7.9)$ & $1(5.8)$ & $2(9.5)$ & 0.02 & $.882^{\dagger}$ \\
\hline & & $\geq 200 \& \leq 300$ & $17(44.7)$ & $8(47.1)$ & $9(42.9)$ & & \\
\hline & & $>300$ & $18(47.4)$ & $8(47.1)$ & $10(47.6)$ & & \\
\hline & \multirow[t]{2}{*}{ Postpartum care } & Yes & $13(34.2)$ & $7(41.2)$ & $6(28.6)$ & 0.66 & .502 \\
\hline & & No & $25(65.8)$ & $10(58.8)$ & $15(71.4)$ & & \\
\hline & \multirow{2}{*}{$\begin{array}{l}\text { Planned } \\
\text { pregnancy }\end{array}$} & Yes & $30(78.9)$ & $12(70.6)$ & $18(85.7)$ & 1.29 & $.426^{*}$ \\
\hline & & No & $8(21.1)$ & $5(29.4)$ & $3(14.3)$ & & \\
\hline & \multirow[t]{2}{*}{ Delivery type } & Natural delivery & $8(21.1)$ & $5(29.4)$ & $3(14.3)$ & 1.29 & $.426^{*}$ \\
\hline & & Cesarean section & $30(78.9)$ & $12(70.6)$ & 18 (85.7) & & \\
\hline & \multirow{2}{*}{$\begin{array}{l}\text { Disease during } \\
\text { pregnancy }\end{array}$} & Yes & $24(63.2)$ & $13(76.5)$ & $11(52.4)$ & 2.34 & .181 \\
\hline & & No & $14(36.8)$ & $4(23.5)$ & $10(47.6)$ & & \\
\hline & \multirow{3}{*}{$\begin{array}{l}\text { Mood during } \\
\text { pregnancy }\end{array}$} & Happy & $14(36.8)$ & $3(17.6)$ & $11(52.4)$ & 2.54 & .111 \\
\hline & & Average & $16(42.1)$ & $10(58.9)$ & $6(28.6)$ & & \\
\hline & & Depressed & $8(21.1)$ & $4(23.5)$ & $4(19.0)$ & & \\
\hline & \multirow[t]{2}{*}{ Feeding } & Breastfeeding & $16(42.1)$ & $5(29.4)$ & $11(52.4)$ & 2.64 & .154 \\
\hline & & $\begin{array}{l}\text { Mixed feeding with } \\
\text { baby formula }\end{array}$ & $22(57.9)$ & 12 (70.6) & $10(47.6)$ & & \\
\hline \multirow{8}{*}{$\begin{array}{l}\text { Premature } \\
\text { infant }\end{array}$} & Sex & Male & $24(63.2)$ & 12 (70.6) & $12(57.1)$ & 0.73 & .506 \\
\hline & & Female & $14(36.8)$ & $5(29.4)$ & $9(42.9)$ & & \\
\hline & \multirow[t]{2}{*}{ Birth order } & First-born & $23(60.5)$ & $11(64.7)$ & $12(57.1)$ & 0.28 & .595 \\
\hline & & Later-born & 15 (39.5) & $6(35.3)$ & 9 (42.9) & & \\
\hline & $\begin{array}{l}\text { Gestational age } \\
\text { (day) }\end{array}$ & & $215.2 \pm 13.3$ & $211.4 \pm 10.4$ & $218.4 \pm 14.6$ & 1.73 & .083 \\
\hline & Birth weight (g) & & $1,522.9 \pm 338.3$ & $1,457.1 \pm 323.2$ & $1,576.2 \pm 348.5$ & 0.94 & .347 \\
\hline & Ventilator care & Yes & $33(86.8)$ & 15 (88.2) & $18(85.7)$ & 0.05 & $>.999^{*}$ \\
\hline & & No & $5(13.2)$ & 2 (11.8) & 3 (14.3) & & \\
\hline
\end{tabular}

${ }^{*}$ Fisher's exact test; ${ }^{\dagger}$ Linear-by-linear association; Cont., control group; Exp., experimental group. 
MCER from the pretest score to posttest score. The control group showed an increase, but the difference was not significant. The experimental group showed a greater change than the control group and the difference was statistically significant. Accordingly, hypothesis 1 was supported.

The experimental group showed a significant decrease in stress from the pretest score to posttest score, as did the control group. The experimental group showed a greater change than the control group and the difference was statistically significant. Accordingly, hypothesis 2 was supported. The experimental group showed a significant decrease in state anxiety from the pretest score to posttest score. The control group showed an increase, but the difference was not significant. The experimental group showed a greater change than the control group and the difference was statistically significant. Accordingly, hypothesis 3 was supported. The experimental group showed a significant decrease in postpartum depression from the pretest score to posttest score. The control group also showed a decrease from the pretest score to posttest score, but the difference was not significant. The experimental group showed a greater change than the control group and the difference was statistically significant. Accordingly, hypothesis 4 was supported (Table 4 ).

\section{DISCUSSION}

This study tested the effects of an eight-session REBT-based emotion regulation program on cognitive changes and negative emotions among mothers of premature infants in the NICU. The results showed that applying the REBT-based emotion regulation program reduced MCER, stress, state anxiety, and postpartum depression.

The experimental group showed a significant decrease in the MCER score, whereas the control group showed an increase. Questioning dissonance was used to examine the evidence of problematic beliefs repeatedly and carefully [25]. It is believed that MCER decreased due to the efforts made by mothers of premature infants to change their irrational beliefs to more realistic and rational beliefs. A study by Kim [26] found that reducing MCER was effective for improving the psychological symptoms of depressed patients since they often use self-blame, catastrophizing, and rumination. Therefore, the decrease in MCER scores of mothers in this study is very meaningful.

After the intervention, both the experimental and control groups showed a significant decrease in stress scores, but the magnitude of the change in stress scores was significantly higher in the experimental group than in the control group. The reason for the reduced stress in control group is believed

Table 3. Homogeneity Testing of Pretest Dependent Variables $(N=38)$

\begin{tabular}{|c|c|c|c|c|c|}
\hline \multirow{2}{*}{ Variables } & Total $(n=38)$ & Exp. $(n=17)$ & Cont. $(n=21)$ & \multirow{2}{*}{ z } & \multirow{2}{*}{$p$} \\
\hline & $\mathrm{M} \pm \mathrm{SD}$ & $\mathrm{M} \pm \mathrm{SD}$ & $\mathrm{M} \pm \mathrm{SD}$ & & \\
\hline Maladaptive cognitive emotion regulation & $34.11 \pm 10.45$ & $34.12 \pm 9.85$ & $34.10 \pm 11.15$ & 0.07 & .941 \\
\hline Stress & $82.61 \pm 9.25$ & $80.12 \pm 9.56$ & $84.62 \pm 8.70$ & 1.50 & .133 \\
\hline State anxiety & $51.11 \pm 8.49$ & $52.65 \pm 9.03$ & $49.86 \pm 8.03$ & 0.94 & .346 \\
\hline Postpartum depression & $12.32 \pm 6.06$ & $12.53 \pm 6.60$ & $12.14 \pm 5.74$ & 0.15 & .883 \\
\hline
\end{tabular}

Cont., control group; Exp., experimental group.

Table 4. Comparison of Outcome Variables between the Two Groups ( $N=38)$

\begin{tabular}{|c|c|c|c|c|c|c|c|c|}
\hline Variables & Groups & $\begin{array}{l}\text { Pretest } \\
\mathrm{M} \pm S D\end{array}$ & $\begin{array}{l}\text { Posttest } \\
M \pm S D\end{array}$ & $\mathrm{z}$ & $p$ & $\begin{array}{l}\text { Amount of change } \\
\mathrm{M} \pm \mathrm{SD}\end{array}$ & $\mathrm{z}$ & $p$ \\
\hline $\begin{array}{l}\text { Maladaptive cognitive } \\
\text { emotion regulation }\end{array}$ & $\begin{array}{l}\text { Exp. }(n=17) \\
\text { Cont. }(n=21)\end{array}$ & $\begin{array}{l}34.12 \pm 9.85 \\
34.10 \pm 11.15\end{array}$ & $\begin{array}{l}23.82 \pm 4.38 \\
37.05 \pm 12.85\end{array}$ & $\begin{array}{l}-3.30 \\
-1.27\end{array}$ & $\begin{array}{l}.001 \\
.200\end{array}$ & $\begin{array}{c}-10.29 \pm 8.24 \\
2.95 \pm 9.40\end{array}$ & -3.88 & $<.001$ \\
\hline Stress & $\begin{array}{l}\text { Exp. }(n=17) \\
\text { Cont. }(n=21)\end{array}$ & $\begin{array}{l}80.12 \pm 9.56 \\
84.62 \pm 8.70\end{array}$ & $\begin{array}{l}64.76 \pm 9.75 \\
79.80 \pm 8.27\end{array}$ & $\begin{array}{l}-3.41 \\
-2.66\end{array}$ & $\begin{array}{l}.001 \\
.008\end{array}$ & $\begin{array}{c}-15.35 \pm 11.89 \\
-4.81 \pm 6.72\end{array}$ & -2.76 & .006 \\
\hline State anxiety & $\begin{array}{l}\text { Exp. }(n=17) \\
\text { Cont. }(n=21)\end{array}$ & $\begin{array}{l}52.65 \pm 9.03 \\
49.86 \pm 8.03\end{array}$ & $\begin{array}{l}38.24 \pm 6.21 \\
50.76 \pm 10.89\end{array}$ & $\begin{array}{l}-3.52 \\
-0.54\end{array}$ & $\begin{array}{r}<.001 \\
.591\end{array}$ & $\begin{array}{c}-14.41 \pm 10.81 \\
0.90 \pm 8.87\end{array}$ & -3.72 & $<.001$ \\
\hline Postpartum depression & $\begin{array}{l}\text { Exp. }(n=17) \\
\text { Cont. }(n=21)\end{array}$ & $\begin{array}{l}12.53 \pm 6.60 \\
12.14 \pm 5.74\end{array}$ & $\begin{array}{r}7.06 \pm 3.44 \\
11.86 \pm 3.81\end{array}$ & $\begin{array}{l}-2.93 \\
-0.36\end{array}$ & $\begin{array}{l}.003 \\
.722\end{array}$ & $\begin{array}{l}-5.48 \pm 5.86 \\
-0.29 \pm 4.71\end{array}$ & -2.62 & .009 \\
\hline
\end{tabular}

Cont., control group; Exp., experimental group. 
to be due to the continuous information and support provided by the medical staff. A previous study [27] reported that mothers of premature babies experienced high levels of stress for 1 year postpartum due to negative perceptions about parental roles and the baby. A reinterpretation of situation-cognitionemotions was used in sessions 4 and 5 to help mothers of premature infants recognize for themselves that their own irrational beliefs were affecting stress, rather than the stressful event itself.

The experimental group showed a significant decrease in state anxiety, whereas the control group showed no significant change. These findings are similar to those reported by Kim et al. [28], who found that the experimental group consisting of mothers of premature infants who received a supportive nursing intervention showed a decrease in anxiety, but the control group showed no significant difference. Meanwhile, a study by Shaw et al. [8] reported that when mothers of premature infants received six sessions of trauma-focused cognitive behavioral therapy, anxiety decreased in both the experimental and control groups, with no significant difference in the level of decrease in anxiety between the two groups. These results are inconsistent with the findings in the present study, but the study by Shaw et al. [8] provides information about the environment and policies of the NICU. In this study, pretest state anxiety scores indicated severe state anxiety [22]. It has been reported that state anxiety may persist until the preterm infant shows comparable growth and development to full-term infants [29]. Therefore, it is necessary to keep an eye on long-term studies on state anxiety of mothers of premature infants after discharge.

This study found that irrational beliefs, such as rumination and catastrophizing, caused an increase in anxiety. Mothers of premature infants showed anxious reactions as they repeatedly thought about their own fault in giving birth prematurely and worried about anything and everything that could happen to their child. Mothers used emotional dissonance in sessions 5 and 6 to change their irrational beliefs to realistic, rational beliefs and to repeatedly express and practice coping statements, which helped reduce anxiety.

The experimental group in the present study showed a significant decrease in postpartum depression, whereas the control group did not. Both the experimental and control groups showed mild postpartum depression, which is an indication of possible severe depression later on. A previous study used the EPDS to investigate postpartum depression in 101 mothers of premature infants at 2-3 weeks after NICU admission and found that $86.1 \%$ of mothers of premature infants had a depression score of more than 12 points [11], underscoring the need for the development of intervention programs and early screening of postpartum depression in mothers during the in- itial period of NICU admission. Regarding international studies on the prevention and intervention of postpartum depression in mothers during the initial period of NICU admission, a study by Melnyk et al. [30] reported that stress, anxiety, and depression were reduced through the outer appearance and behavior of the child and parent education. A study by Shaw et al. [8] reported that psychological trauma and depressive symptoms of parents were significantly reduced through an invention combining psychological trauma-focused cognitive behavioral therapy and parent education. As shown, parent education interventions that provide information regarding premature infants and cognitive behavioral therapy approaches were found to be effective in reducing depression in mothers of premature infants.

It is believed that postpartum depression in mothers of premature infants in the NICU was significantly reduced in the present study through the process of finding the cause of depressive emotions based on REBT theory and correcting those causes. This study required the participants to recall the situation and record their thoughts whenever depressive emotions occurred in daily life, outside of the program sessions. Therefore, postpartum depression was reduced through the cognitive task of having mothers explore irrational beliefs and take part in active dissonance. The most significant finding of the present study is that reducing postpartum depression in mothers of premature infants during the initial stage of NICU admission through cognitive, emotional, and behavioral dissonance in an REBT-based emotion regulation program could prevent the exacerbation of postpartum depression. A reduction in stress, state anxiety, and postpartum depression can ultimately contribute to the development of a positive parentchild relationship by enabling the mother to have a positive perception of her premature infant.

This study was unable to identify long-term effects due to its nature, and because follow-up assessments after discharge were not conducted. In addition, this study was conducted among a small number of mothers at a single institution due to difficulties in recruiting participants. This study also had the limitation of not controlling for the medical conditions of premature infants, familial support, and trait anxiety of mothers, all of which could influence negative emotions.

Despite these limitations, the present study identified and validated the effects of a REBT-based intervention on negative emotions of mothers of premature infants in the NICU, thereby verifying the usefulness and applicability of REBT theory in nursing. With studies on psychological intervention for reducing postpartum depression in mothers of premature infants in the NICU being scarce in South Korea, the present study produced findings that could contribute to expanding research on REBT-based postpartum depression inventions 
for mothers of premature infants in the NICU. Moreover, the present study was meaningful in that it applied an REBTbased emotion regulation program to mothers of premature infants in the NICU to correct their thinking and reduce negative emotions to help enhance their mental health.

\section{CONCLUSION}

This study was conducted to develop and test the effects of an emotion regulation program for mothers of premature infants in the NICU based on REBT theory. The REBT-based emotion regulation program applied in the present study was an interventional program designed to reduce negative emotions of mothers by correcting their thoughts. After the intervention, mothers showed decreased MCER and negative emotions, which demonstrated that the REBT-based emotion regulation program was an effective intervention for reducing negative emotions in mothers of premature infants in the NICU. Therefore, an REBT-based emotion regulation program could be used in the future to reduce negative emotions in mothers of premature infants in the NICU.

Based on the findings of the study, the following steps are recommended: 1) It is necessary to develop a strategy for implementing REBT-based emotion regulation programs in clinical practice for use in the NICU with consideration of utilization of professional personnel and cost-effectiveness; 2) additional studies that include long-term follow-up will be needed to verify the sustainability of the effects of the program in reducing negative emotions; and 3) since the present study could not identify behavioral changes, which take longer to develop than cognitive and emotional changes, future studies should test the effects of the program on behavioral changes.

\section{Conflict of interest}

No existing or potential conflict of interest relevant to this article was reported.

\section{Data availability}

Please contact the corresponding author for data availability.

\section{REFERENCES}

1. Statistics Korea. 2019 Birth tables for Korea [Internet]. Daejeon: Statistics Korea; 2019 [cited 2020 September 14]. Available from: http://kosis.kr/index/index.do

2. Tami A, Harmon RJ. Relationships between preterm infants and their parents: Disruption and development. Infant Behavior and
Development. 2003;24(2):13-20.

https://doi.org/10.1016/0163-6383(90)90042-7

3. Altimier L, Phillips RM. The neonatal integrative developmental care model: Seven neuroprotective core measures for family-centered developmental care. Newborn and Infant Nursing Reviews. 2013;13(1):9-22. https://doi.org/10.1053/j.nainr.2012.12.002

4. Choi E, Lee Y. A mother's experience of hospitalization of her newborn in the neonatal intensive care unit. Child Health Nursing Research. 2018;24(4):407-419.

https://doi.org/10.4094/chnr.2018.24.4.407

5. Holditch Davis D, Bartlett TR, Blickman AL, Miles MS. Posttraumatic stress symptoms in mothers of premature infants. Journal of Obstetric, Gynecologic, Neonatal Nursing. 2003;32(2):161-171. https://doi.org/10.1177/0884217503252035

6. Jeon CS. Family stress, resiliency and adaptation perceived by parents of the hospitalized prematurity in NICU [dissertation]. Seoul: Hanyang University; 2011. p. 1-92.

7. Garnefski N, Kraaij V, Spinhoven P. Negative life events, cognitive emotion regulation and emotional problems. Personality and Individual Differences. 2001;30(8):1311-1327.

https://doi.org/10.1016/s0191-8869(00)00113-6

8. Shaw RJ, St John N, Lilo EA, Jo B, Benitz W, Stevenson DK, et al. Prevention of traumatic stress in mothers with preterm infants: A randomized controlled trial. Pediatrics. 2013;132(4):e886-e894.

https://doi.org/10.1542/peds.2013-1331

9. Vigod SN, Villegas L, Dennis CL, Ross LE. Prevalence and risk factors for postpartum depression among women with preterm and low-birth-weight infants: A systematic review. International Journal of Obstetrics and Gynaecology. 2010;117(5):540-550. https://doi.org/10.1111/j.1471-0528.2009.02493.x

10. Lee JY, Ju HO. Predictors of early postpartum depression in mothers of preterm infants in neonatal intensive care units. Child Health Nursing Research. 2014;20(2):87-95. https://doi.org/10.4094/chnr.2014.20.2.87

11. Song JE, Ko JM. Influencing factors on maternal role adjustment among the primipara women in the first year after childbirth. Journal of the Korean Society of Maternal and Child Health. 2016; 20(3):284-296. https://doi.org/10.21896/jksmch.2016.20.3.284

12. Treyvaud K, Doyle LW, Lee KJ, Roberts G, Lim J, Inder TE, et al. Social-emotional difficulties in very preterm and term 2 year olds predict specific social-Emotional problems at the age of 5 years. Journal of Pediatric Psychology. 2012;37(7):779-785. https://doi.org/10.1093/jpepsy/jss042

13. Ellis A. Changing rational-emotive therapy (RET) to rational emotive behavior therapy (REBT). Journal of Rational-Emotive and Cognitive-Behavior Therapy. 1995;13:85-89.

https://doi.org/10.1007/bf02354453

14. Jackson CJ, Izadikah Z, Oei TPS. Mechanisms underlying REBT in mood disordered patients: Predicting depression from the hybrid model of learning. Journal of Affective Disorders. 2012;139(1):30- 
39. https:// doi.org/10.1016/j.jad.2011.09.025

15. Shin KA. Effect of the cinema therapy program for middle-aged women with depression. Journal of Digital Convergence. 2018; 16(10):511-522. https://doi.org/10.14400/JDC.2018.16.10.511

16. Park KA, Back HS, Han JS. The effects of REBT group counseling on the job stress, positive affect, negative affect and self-esteem of nurses. Korea Journal of Counseling. 2007;8(3):951-963.

https://doi.org/10.15703/kjc.8.3.200709.951

17. Kim N, Jin J. The Meta-analysis on the effectiveness of cognitive behavioral therapy programs. Journal of Humanities and Social Science. 2019;10(4):1663-1676. https://doi.org/10.22143/hss21.10.4.119

18. Kim EY, Hwang SY. Development and evaluation of a small group-based cardiocerebrovascular disease prevention education program for male bus drivers. Journal of Korean Academy of Nursing. 2012;42(3):322-332. https://doi.org/10.4040/jkan.2012.42.3.322

19. Kim SH. A study on relationships among the stressful events, cognitive emotion regulation strategies and psychological well-being. Journal of Student Guidance and Counseling. 2008;26:5-29.

20. Miles MS, Funk SG, Carlson J. Parental stressor scale: Neonatal intensive care unit. Nursing Research. 1993;42(3):148-152. https://doi.org/10.1097/00006199-199305000-00005

21. Hahn DW, Lee CH, Chon KG, Spielberger CD. Korean version State-Trait Anxiety Inventory for Adults Form YZ [Internet]. Seoul: Insight of Psychology; 2018 [cited 2018 April 20]. Available from: https://inpsyt.co.kr/psy/item/view/STAIKYZ_CO_SG

22. Spielberger CD, Gorsuch RL, Lushene RE. Manual for the State Trait Anxiety Inventory: STAI. 10th ed. Palo Alto, CA: Consulting Psychologists Press; 1970. p. 24.

23. Cox JL, Holden JM, Sagovsky R. Detection of postnatal depression:
Development of the 10-item Edinburgh Postnatal Depression Scale. British Journal of Psychiatry. 1987;150(6):782-786.

https://doi.org/10.1192/bjp.150.6.782

24. Han KW, Kim MJ, Park JM. The Edinburgh Postnatal Depression Scale, Korean version: Reliability and validity. Journal of the Korean Society Biological Therapies in Psychiatry. 2004;10(2):201- 206.

25. Ellis A, MacLaren C. Rational emotive behavior therapy: A therapist's guide. 2nd ed. Seo SK, Kim Yh, translator. Atascadero, CA: Impact; 2007. p. 85-144.

26. Kim NY. The relationships between cognitive emotion regulation strategies and stress reaction in psychiatric outpatients: Centered on major depression disorder [master's thesis]. Chuncheon: Kangwon National University; 2013. p. 1-43.

27. Holditch-Davis D, Santos H, Levy J, White-Traut R, O'Shea TM, Geraldo V, et al. Patterns of psychological distress in mothers of preterm infants. Infant Behavior and Development. 2015;41:154163. https:// doi.org/10.1016/j.infbeh.2015.10.004

28. Kim YH, Kim HJ, Lee EJ, Lee JY, Lee MK. Effects of the home health care program on maternal anxiety and confidence, premature infants' growth and hospital utilization. Journal of the Korean Society of Maternal and Child Health. 2015;19(2):189-200. https://doi.org/10.21896/jksmch.2015.19.2.189

29. Park JY, Bank KS. Knowledge and needs of premature infant development and rearing for mothers with premature infants. Korean Parent Child Health Journal. 2013;16(1):17-26.

30. Melnyk BM, Feinstein NF, Alpert-Gillis L, Fairbanks E, Crean HF, Sinkin RA, et al. Reducing premature infants' length of stay and improving parents' mental health outcomes with the Creating Opportunities for Parent Empowerment (COPE) neonatal intensive care unit program: A randomized, controlled trial. Pediatrics. 2006; 118(5):e1414-e1427. https://doi.org/10.1542/peds.2005-2580 